\title{
The Empirical Research on New Urbanization In Liaoyang County
}

\author{
De-yong Ma, Ling-ling Luo \\ School of Marxism, Northeastern University, Liaoning Province, China
}

\begin{abstract}
Liaoyang is a county which the population grows slowly and has less existing urban population in Liaoning province. From 2003 to 2013, the county's economic develops faster but weaker and the most people in agricultural management for living. This article selects it as the research object, through investigation and study found: Although the agricultural management in Liaoyang county is the main way of employment population but not the dominant pillar industry, its industrial structure is onefold, the proportion of iron and steel industry in the whole industrial transformation is high and under the high pressure. This article puts forward new industrialization provide economic and technical basis for new urbanization, with distinctive industrialization promotes the development of new urbanization, with new urbanization drives the distinctive industrialization.
\end{abstract}

Keywords-Agricultural Economy, New Urbanization, New industrialization, Distinctive industrializatio

\section{辽阳县新型城镇化的实证探讨}

\author{
马德勇, 罗玲玲 \\ 东北大学马克思主义学院, 沈阳市, 辽宁省, 中国
}

摘 要 辽阳县是辽宁省一个人口低速增长, 且现有城镇人口少的县, 在 2003-2013 年期间, 它的经济发展较快但县域经济发展 较弱, 且有大半的人口以农业经营为生。本文选取其为研究对象, 通过调查研究发现: 辽阳县农业经营虽是人口就业的主要途径但不 是占主导地位的支柱产业, 工业结构单一, 钢铁产业在工业中比例极高且转型压力大。本文提出以新型工业化为新型城镇化提供经济、 技术基础, 以特色产业化促进新型城镇化发展, 以新型城镇化带动新型工业化和特色产业化。

关键词 农业经济, 新型城镇化, 新型工业化, 特色产业化

\section{1. 引言}

2015 年春节期间, 上海大学博士生王磊光的文章《一 位博士生的返乡笔记: 近年情更怯, 春节回家看什么》引 发了與论的关注。王否光在文中描述了他的故乡的一些现 状, 如农村人与人之间联系的失落, 年青人衡量成功的标 准等。[1]本文作者因为一直对城镇化问题非常感兴趣并且 目前的工作与农村密不可分, 所以读过这篇文章后思考更 多的是我国农村经济的发展问题、新型城镇化的实现等相 关问题。本文以辽宁省辽阳市辽阳县为例, 对以上问题提 出自己的一点思考, 试图见微知著, 尝试找出符合现实国 情和地域特点的新型城镇化之路。

\section{2. 辽阳县新型城镇化的现实基础}

辽阳市辽阳县面积为 2485 平方公里, 人口 47.8 万, 北靠 辽阳市区, 南抱鞍山市区, 东接本溪市区, 西连辽中县。 辽阳县交通便利, 地处哈大高速、沈阳经济区高速环线的 十字轴线上。本文研究的数据是基于对辽阳县 2003 年-2013 年的各项调研报告。

\section{1 辽阳县人口低速增长, 现有城镇人口少}

自本世纪初起, 辽阳县的人口就处于自然增长缓慢的 状态, 增长率不足 $0.6 \%$ 。根据六普人口数据显示, 辽阳县 的人口年龄结构呈橄榄型分布, 详细的说就是辽阳县 30-60 岁占了人口的绝大多数, 而新出生的人口越来越少, 60 岁 以上人口比例为 $16 \%$, 而在这十年间, 外来人口仅为 1.5 
万。显然, 辽阳县与我国很多市县一样, 已经进入老龄化 社会。辽阳县城人口约 10 万人, 建设面积 16.2 平方公里, 刚刚达到小城市标准。

\section{2 经济发展较快但县域经济发展较弱}

自 2003-2013 年期间, 辽阳县的 GDP 平均增速为 18\%, 而全省的平均增速是 $16.3 \%$, 辽阳县的 GDP 平均增速是高 于辽宁省的平均增速的, 与省内其它县相比较比较而言, 辽阳县经济发展是比较快的。其中 2013 年辽阳县的人均 GDP 为 58075 元/人, 这个数据又略低于全省平均的 61680 元/人。经济发展较快, 但县域经济发展较弱, 地方财政一 般预算收入在 2012 年全省排名在 22 位, 数额远远落后于 瓦房店、大洼县、庄河等地区。

\section{3 人口就业以农业为主}

在辽阳县所辖的十五个乡镇中, 其中十二个乡镇的大 部分人口从事农业种植和养殖, 这部分人口可以达到 $70 \%$ 左右, 而只有兴隆镇、刘二堡镇及县政府的所在地首山镇, 本地务工或经商的人口、外来人口比重接近了 $50 \%$ 。这样 的务农比例决定了下面的数据, 在这些乡镇中, 十三个乡 镇的收入以农业经营为主, 非农务工和经商收入为补充; 只有首山镇和兴隆镇两者所占比重反了过来, 基本以非农 务工和经商收入为主。

\section{3. 辽阳县新型城镇化的问题及难点}

3.1 农业经营虽是人口就业的主要途径但不是占主导地位 的支柱产业

根据辽阳县各乡镇人口就业及收入所占的比重来看, 农业经营目前占据着主导地位。因整个县的地理环境, 决 定了地处东部的乡镇以林果种植为主, 如下达河乡、隆昌 镇、八会镇等七个镇; 而地处西部的乡镇如刘二堡镇、唐 马寨镇、小北河镇等八个镇是以粮食种植和蔬菜种植以主。 所有农产品的销售主要途径是以卖给收购商为主, 而值得 一提的是其中农产品加工企业发展较快, 村民集体经济组 织逐步发挥市场职能。全面农民专业合作社达到 599 家, 家庭农场 32 家, 联合社 2 家。农产品的销售又以本县为主, 随着区域性农产品基地发展的加快, 获得绿色食品认证企 业达到 6 家, 无公害农产品认证 85 个, 有机食品认证 1 家。 因此也有一部分农产品销往邻近省市, 如寒岭销往辽阳市 区; 穆家、八会销往鞍山市区; 甜水、吉洞销往本溪; 小 北河、黄泥洼和柳壕等销往其他省市, 北菜南运基地初见 成效。
2013 年辽阳县的一、二、三产的产业结构比是 9.3:74:16.7, 农业所占比重连 10\%都不到, 可是全县却是一 大半人口需要以此为主要收入。这种状况是极不合理的, 也意味着辽阳县的农业养活着全县这大半的人口, 却无法 让他们过上富足的生活, 更谈不上与城市居民一样, 享有 同等的权利及生活, 城镇化无从谈起。

\section{2 工业结构一钢独大且转型压力大}

辽阳县的铁矿石控制资源量可达 6 亿吨, 辽阳县菱镁 矿已探明储量为 6324 万吨, 这两种矿产资源占有量都居国 内前列。自然而然, 辽阳县的工业企业大都依此为生, 其 中治金行业在工业经济结构中占据了 $65 \%$, 装备制造业占 了 $13 \%$, 矿山建材行业占了 $11 \%$, 轻工纺织业只占 $8 \%$, 而农产品加工更是只占了 $3 \%$ 。真正是产业结构单一, 一钢 独大的局面。辽阳县也是鞍钢和本钢重要的铁矿基地, 负 责给鞍钢配套, 承接钢铁产业转移, 钢铁产业在工业中比 例最高时占 $90 \%$ 。2012 年钢铁产量 620 万吨, 产值 205 亿 元, 约占辽阳县工业总产值 $40 \%$; 已经形成刘二堡工业区 和向阳工业区两大钢铁产业基地。但是这些企业的规模都 比较小, 工艺生产水平较低, 造成的高能耗和高污染问题 都非常突出。并且, 这种资源型工业企业为主导的产业结 构就业带动能力不足, 辽阳县的城镇化率仅约为 $40 \%$, 辽 阳县城镇化的路径主要是外来人口及农村人口进城。

2013 年 10 月, 国务院发布了《国务院关于化解产能 严重过剩矛盾的指导意见》, 提出优化产业布局, 压缩钢铁 产能总量 8000 万吨以上的目标。淘汰钢铁企业, 淘汰落后 产能, 成为辽阳必须面对的问题。整个钢铁产业转型升级 压力大, 辽阳县经济发展面临严峻的挑战。

\section{4. 辽阳县新型城镇化的路径探析}

自建国起, 我国就已进入城镇化之路, 但城镇化的进 程是自改革开放才加大了步伐, 尤其是近十来年城镇化以 突飞猛进的速度前行。但我国在实现城镇化这一历史过程 中, 出现了各种问题, 如资源消耗高、环境事件频发、城 乡差距加大、片面追求城市规模扩大、城乡二元结构矛盾 突出等问题。这些矛盾及问题促使我们对已有城镇化的方 式进行反思, 对城镇化的内涵做了重新界定, 提出了“新型 城镇化” 的概念。有学者把新型城镇化与旧的城镇化模式相 比较, 认为新型城镇化应该是以科学和谐、节约集约、生 态宜居、工业化与城镇化互动、城乡待遇一体、城乡统筹 发展为特征的城镇化。[2]本文认为新型城镇化的实现与新 型工业化、特色产业化密不可分, 三化统筹发展是兼顾三 化目标和利益的有力保障。 


\section{1 实现新型工业化为新型城镇化提供经济、技术基础}

有学者认为新型工业化是中国现代化道路的现实

选择, 新型工业化与城市化相互影响、相互促进。新型工 业化给中国城市化发展带来新的机遇, 提出新的要求, 也 提供了重要动力。[3]如果说新型工业化是带动城镇化的重 要动力, 那么本文认为新型工业化为新型城镇化提供的是 经济、技术基础。

辽阳县的矿产资源本底决定辽阳县在未来相当长 时间内仍将延续资源型产业主导的发展模式，但一钢独大 的局面必须终止。同时, 治金行业结构必须进行调整, 钢 铁产业链进行延伸，向特种铸件、型材、装备制造业发展。 实现冶金行业转型升级, 须坚持淘汰落后钢铁产能, 加强 资源（如土地资源、生产指标）整合, 企业兼并, 推动钢 铁产业在园区集聚发展; 县内需要建立新的主导产业体系, 比如装备制造产业、新兴产业 (新材料、新能源), 与冶金 产业实现三足鼎立的局面。

无论是建立新的主导产业, 还是仅仅是一个产业的产 业链延伸, 都离不开技术的创新, 以实现企业利益最大化 为目的的技术创新，也是实现新型工业化的手段及方法。 技术创新可以避免困扰着辽阳人的高能耗和高污染问题, 又可以实现县域经济的长足发展。

\section{2 以特色产业化促进新型城镇化}

特色是一个事物所特有的区别于其他事物的本质属 性。“特色”就是“独有”, 就是“区别于其它”, 也就是独一无 二之“魅力”。要确实研究和把握本地区的“特色”优势, 才 能为市场提供具有特色的产品和服务。在辽阳县, 农业经 营保证着大半个县的人口就业, 但在产业结构中却占据不 到 $10 \%$ 的比重。新型城镇化 “化”的是人, 如果这个大半个 县人口所依赖为生的产业, 仍然是如此状态的话, 辽阳县 的新型城镇化将成为空谈。

辽阳县具有优良的生态环境资源, 它的森林覆盖率达 到了 $50 \%$, 并且拥有多个自然保护区。目前的地处东部林 区的乡镇主要是林果种植为生, 那么依托良好的生态资源,
依托沈阳经济区的崛起, 本县发达、便利的交通条件, 完 全可以把东部林区开发成生态导向的旅游、休闲、养生服 务业。

同时辽阳县也是辽河平原重要的商品粮基地, 在现有 的农业产业基础之上应打造绿色农产品基地, 发展现代高 效农业、生态农业。并与休闲农业相结合，按照服务城市、 融入城市的目标, 以构建特色产业体系为依托, 以高效化、 特色化、品牌化、信息化为路径, 重点加快农业增长方式 转变, 推进农业产业化经营, 创新农业经营体制。

\section{3 以新型城镇化带动新型工业化和特色产业化发展}

正如前文所介绍的，辽阳县特殊的地理位置使得其新 型城镇化的发展找到了可依托的对象。沈阳经济区正在全 面的腾飞发展，任何地区的发展都不是封闭的、静止的， 而是不断运动着的, 向外辐射着的, 也需要其它地区的承 接。辽阳县可以承接沈阳经济区的产业和功能转移, 并且 融入区域产业、服务、物流甚至是交通体系。并且向北可 与辽阳市对接, 向南可于鞍山市对接, 区域的融入是必要 且有益的。对现有乡镇通过转移就业带动农业人口向城镇 聚集, 人口的城镇化需要产业的转型, 以增强对城镇化人 口的接纳能力, 新型工业化被推动发展。新型城镇化需加 快城乡交通, 推进基础设施大规模的建设, 公共服务体系 也需要相应跟上, 以上这些必将促进农村特色产业的发展。

新型城镇化、新型工业化、特色产业化的统筹发展, 是实现三化目标及各自利益的有力保障，如何协调三化发 展过程中的问题，如何兼顾每一化的目标，更需要实践去 探索。

\section{参考文献(References)}

[1] http://www.nandu.com/html/201502/25/1051261.html, 2015-2-25.

[2] LI Yi-ning. China's roads and New Urbanization. Beijing: The commercial press, 2012, pp. 266.

[3] XIE Jun-gui. Development of China' s Urbanization under New Industrialization. China Soft Science, no. 7, pp. 28-33, 2002. 